\title{
Implicit and explicit memory models
}

\author{
HENRY L. ROEDIGER III \\ Purdue University, West Lafayette, Indiana 47907
}

\begin{abstract}
In describing phenomena associated with memory, people typically rely on an implicit or intuitive theory that assumes the mind is like a space in which memories are stored, just as objects are stored in physical space. Utilization of information is often described as a search process through the space. The argument is briefly presented that almost all explicit memory theories embody the same assumptions of spatial storage and search as those in our implicit theory. Possible reasons for this state of affairs are examined and some alternative nonspatial approaches, as yet not very popular, are presented.
\end{abstract}

Psychologists and philosophers interested in understanding human memory have produced a remarkable variety of theories and models to explain its functioning. The purpose of this paper is to describe briefly some general characteristics of these theories, but first I would like to consider a different line of inquiry inspired by the psychology of personality. Personality psychologists make a distinction between explicit and implicit personality theories. Explicit personality theories are those proposed and tested by psychologists. Implicit personality theories, on the other hand, are attempts to characterize the intuitive ideas that each of us has and uses to explain others' behavior.

It may be interesting to ask whether we can similarly investigate implicit memory theories. To the extent that people are curious about their own memories, we might expect that they have developed some ideas, however crude, to explain how their memories work. What kind of intuitive memory theories do most people have?

One source of evidence for an answer to this question may come from an analysis of the expressions people use to characterize their memories. From an examination of such figures of speech, it seems that one particular implicit memory theory is in common use. We basically assume that the mind consists of a space in which information is stored, just as objects are stored in physical space (Jaynes, 1976, pp. 54-56). This leads quite naturally to the view of retrieval as a search for the objects in this space. As Jaynes pointed out, we think of the mind as a place that holds things. We speak of keeping ideas in mind or of memories being in the front, back, or tops of our minds. Memories may be in the dark corners or dim recesses or they may be out of or beyond one's mind. Some people are said to have broad, deep, or open minds, while others' minds are narrow, shallow, or closed. We speak of allowing room for new ideas that must sink in or penetrate the mind. When new facts can be understood in terms of existing knowledge, they seem to fall into place. When it is difficult to retrieve information, the mind is searched for the lost memories. In brief, we normally speak of our memories (or minds) as spaces in which memories are stored.

The main point is that, for whatever reasons, almost all formal theories and models of memory that have been developed by psychologists and philosophers can be seen as embodying the same underlying assumptions as those in our implicit memory theory. Almost all theories assume that (1) memory can be considered a mental space, (2) memories are like objects in this space, and (3) retrieval is a search process for these mental objects. A great many different metaphors have been used to explain various phenomena of memory, but almost all have the same basic character.

Presented in Table 1 is a relatively complete, but certainly not exhaustive, list of metaphors and analogies that philosophers and psychologists have used to characterize memory. The metaphors were placed into three groups, based on my own judgment and that of a few friends. In Column A are analogies where memory is generally considered a receptacle containing objects. Thus, for example, memory has been conceived as a purse, a library, a set of storehouses, a workbench, a conveyor belt, and so on. In these cases, memories or memory traces are conceived as objects in these spaces, and the process of retrieval is considered as a search through the space for the object memories. In short, the fundamental assumptions of spatial storage and search embodied in the analogies in Column $\mathbf{A}$ are the same as those in our implicit memory theories.

Listed in Column B are four quite influential proposals that are also basically spatial in character, but which do not provide an explicit object of comparison for memory. These ideas may all be loosely grouped under "organizational theories" of memory. In each of the proposals, memories are considered to be spatially distributed, and retrieval, in those theories that explicitly deal with that process, is conceived as a search determined by the way the information is stored.

It is likely that the proposals listed in the A and B columns in Table 1 include most of the important theoretical ideas that psychologists have entertained concerning memory. Of course, some of the ideas 
Table 1

Metaphors and Analogies Used to Characterize Memory

Column A: Spatial Analogies with Search

wax tablet (Plato; see Hamilton, 1961)

gramophone (Pear, 1922)

aviary (Plato; see Hamilton, 1961)

house (James, 1890)

rooms in a house (Freud, 1932/1952)

mystic writing pad (Freud, 1940/1950)

switchboard (see John, 1972)

purse (Miller, 1956)

leaky bucket or sieve (Miller, 1956)

junk box (Miller, 1963)

bottle (Miller, Galanter, \& Pribram, 1960)

computer program (Simon \& Feigenbaum, 1964)

stores (Atkinson \& Shiffrin, 1968)

workbench (Klatzky, 1975)

cow's stomach (Hintzman, 1974)

pushdown stack (Bernbach, 1969)

acid bath (Posner \& Konick, 1966)

library (Broadbent, 1971)

dictionary (Loftus, 1977)

keysort cards (Brown \& McNeill, 1966)

conveyor belt (Murdock, 1974)

tape recorder (see Posner \& Warren, 1972)

subway map (Collins \& Quillian, 1970)

garbage can (Landauer, 1975)

Note-Lists of entities to which memory has been compared are in Columns $A$ and $C$. Column $A$ contains analogies where memory is considered a receptacle containing objects. In Column $B$ are other theories that have a spatial character but no explicit object of comparison. In Column $C$ are listed some other analogies that have been used to explain memory.

have not been seriously entertained, and other important ideas, such as Estes' (1959) stimulus sampling theory and Paivio's (1969) dual coding hypothesis, are not represented. Still, the point can be made that almost all the influential theories in Columns A and B of Table 1 agree in their basic assumptions and differ mainly in details. At the risk of putting the case too boldly, it is as if psychologists of memory have produced many variants on one general theory.

This seems a rather remarkable state of affairs, and an analysis of its causes would be interesting. Jaynes (1976) argued that humans invented the spatial metaphor for describing their newly discovered consciousness some 2,000 years ago. Since humans needed a way of describing the unknown inner world, they used the familiar terms of describing objects in actual physical space to explain the inner workings of the invented mental space. Thus memories, ideas, and thoughts are described as actual objects populating this inner mental space. It is very interesting to consider the terms commonly used to describe thought processes in this regard. In a great many cases, terms derived from visual perception are used, as though we actually perceive the object thoughts in the mind space. Ideas are described as bright, dim, hazy, or fuzzy. We may approach a problem from a particular perspective or viewpoint and then see its solution unless it happens to be obscure. A good solution is described as brilliant, and the person who found it is described as bright for perceiving the solution to the problem, and so on.
In a similar vein, mental processes are often described in terms that apply to actual behavior in a physical space. We speak of storing, searching for, and locating memories. We organize our thoughts, look for memories that have been lost, and, if we are fortunate, find them. Adjectives used to describe mental behavior are borrowed from those used to describe physical behavior, such as active, nimble, or quick minds, on the one hand, and slow or sluggish minds, on the other.

Another source of memory metaphors, which can be confirmed by a glance at Table 1 , is the advance in the technology of keeping records and storing knowledge. One of the first metaphors for memory was the impression of a seal on a wax tablet, which was the way of storing information at that time. With advances in the technology of record keeping, human memory has been likened in all seriousness to a gramophone, tape recorder, telephone switchboard, library, dictionary, computer, and hologram. As Skinner (1976, pp. 119. 120) pointed out, cognitive psychologists assume that there is the internal equivalent of some record-keeping process; thus, every new development in the technology of information storage and transmission is seized upon as the new model for the mind. It seems that, as long as we are willing to entertain theoretical speculations about cognitive processes, the technology of information storage is as good a place as any to seek theoretical inspiration. However, observation of this fact may make us a bit more humble about our current theories. It may well be that in 25 years the computer metaphor and the 
information processing viewpoints that reign today will seem as dated as the telephone switchboard, gramophone, or wax tablet metaphors do now.

I have argued that there are few alternatives to the spatial storage and search metaphors for describing the workings of human memory. However, some metaphorical alternatives that have been mentioned are listed in Column C of Table 1. As yet, none of the approaches listed has received much attention, and none yet claims to serve as a general rival to the spatial storage and search metaphors. However, one idea that may eventually lead to a general alternative is the notion of remembering as a resonance process. This idea was first suggested around the turn of the century, but in the last several years it has appeared in a half-dozen papers as a model for retrieval, with the fullest treatments being given in the papers by Lockhart, Craik, and Jacoby (1975) and Ratcliff (1978). The basic idea is that, when one retrieves information, the explicit or implicit cues in the retrieval environment resonate with stored information, just as ringing a tuning fork produces sympathetic vibrations in other tuning forks. There is also a common expression, the basis for an alternative implicit memory theory, founded on the resonance metaphor. We say that a familiar idea rings $a$ bell. The analogy between retrieval and resonance can be followed in other directions. However, it may eventually provide a general alternative to the spatial storage and search metaphor. Although assumptions need to be made about information storage under the resonance metaphor, there is no need to assume that memories are objects deployed in space. Similarly, retrieval is not conceived as a process of search, any more than sound waves emitted by one tuning fork can be said to "search for" similar tuning forks to cause them to vibrate. It is also the case that the retrieval assumptions in the resonance metaphor are quite similar to those in the holographic analogy (Cavanaugh, 1976).

It might also be argued that it is as fruitful, or more fruitful, to describe our experimental results in terms of more abstract general principles rather than rely on models based on concrete analogies to things in our environment. Such ideas as the encoding specificity hypothesis (Tulving \& Thomson, 1973) or Kolers' (1973) work on memory operations serve as examples of this approach. Issues concerning the relative merits of metaphorical and abstract explanatory attempts have been aired by Hesse (1966); certainly, in such a relatively new enterprise as the psychology of memory, both approaches may profitably be pursued simultaneously.

\section{REFERENCES}

ANDerson, J. R., \& Bower, G. H. Human associative memory. Washington, D.C: V. H. Winston, 1973.

Atkinson, R. C., \& Shiffrin, R. M. Human memory: A proposed system and its control processes. In $\mathrm{K}$. W.
Spence \& J. T. Spence (Eds.), The psychology of learning and motivation (Vol. 2). New York: Academic Press, 1968.

BARTLETt. F. C. Remembering: $A$ study in experimental and social psychology. Cambridge, England: Cambridge University Press, 1932.

Bernbach, H. A. Decision processes in memory. Psychological Review, 1967, 74, 462-480.

BernBACH. H. A. Replication processes in human memory and learning. In G. H. Bower \& J. T. Spence (Eds.), The psychology of learning and motivation (Vol. 3). New York: Academic Press. 1969.

Broadbent. D. E. Decision and stress. New York: Academic Press, 1971.

Brown, R., \& McNeill, D. The tip-of-the-tongue phenomenon. Journal of Verbal Learning and Verbal Behavior, 1966, 5, 325-337.

Cavanaugh. J. P. Holographic and trace strength models of rehearsal effects in the item recognition task. Memory \& Cognition, 1976, 4, 186-199.

Collins, A. M., \& Quillian, M. R. Facilitating retrieval from semantic memory: The effect of repeating part of an inference. Acta Psychologica, 1970, 33, 304-314.

Estes. W. K. The statistical approach to learning theory. In S. Koch (Ed.), Psychology: A study of a science (Vol. 2). New York: McGraw-Hill, 1959.

FreUd, S. A general introduction to psychoanalysis. New York: Washington Square Press, 1952. (Originally published in 1932.)

Freud, S. A note upon the "mystic writing pad." In J. Strachey (Ed.), Collected papers of Sigmund Freud. London: Hogarth Press, 1950. (Originally published in English, 1940.)

Hamilton, E. Plato: The collected dialogues. New York: Bollingen Foundation, 1961.

Hesse. M. B. Models and analogies in science. South Bend, Ind: University of Notre Dame Press, 1966.

Hintzman, D. L. Psychology and the cow's belly. The Worm Runner's Digest, 1974, 16, 84-85.

James, W. Principles of psychology. New York: Holt, 1890.

JAYNES, J. The origin of consciousness in the breakdown of the bicameral brain. Boston: Houghton-Mifflin, 1976.

John, E. R. Switchboard versus statistical theories of learning and memory. Science, 1972, 177, 849-864.

Klatzky, R. L. Human memory: Structure and processes. San Francisco: Freeman, 1975.

Kolers, P. A. Remembering operations. Memory \& Cognition, 1973, 1, 347-355.

Kolers, P. A., \& Palef, S. R. Knowing not. Memory \& Cognition, 1976, 4, 553-558.

LANDAuer, T. K. Memory without organization: Properties of a model with random storage and undirected retrieval. Cognitive Psychology, 1975, 7, 495-531.

Lockhart, R. S., Craik, F. I. M., \& Jacoby, L. Depth of processing, recognition, and recall. In J. Brown (Ed.), Recall and recognition. New York: Wiley, 1975.

Loftus, E. F. How to catch a zebra in semantic memory. In R. Shaw \& J. Bransford (Eds.), Perceiving, acting and knowing. Hillsdale, N.J: Erlbaum, 1977.

Mandler, G. Organization and memory. In K. W. Spence \& J. T. Spence (Eds.), The psychology of learning and motivation (Vol. 1). New York: Academic Press, 1967.

Miller, G. A. Human memory and the storage of information. IRE Transactions on Information Theory, 1956, Vol. IT-2, 129-137.

Miller, G. A. Comments on Professor Postman's paper. In C. N. Cofer \& B. S. Musgrave (Eds.), Verbal behavior and learning. New York: McGraw-Hill, 1963.

Miller, G. A., Galanter, E., \& Pribram, K. H. Plans and the structure of behavior. New York: Holt, 1960.

Murdock. B. B. Human memory: Theory and data. Hillsdale, N.J: Erlbaum, 1974.

Paivio. A. Mental imagery in associative learning and memory. Psychological Review, 1969, 76, 241-263. 
PEAR, T. H. Remembering and forgetting. London: Methuen, 1922.

Posner. M. I., \& Konick, A. F. On the role of interference in short term retention. Journal of Experimental Psychology, 1966, 72. 221-231.

Posner, M. I., \& WARren, R. E. Traces, concepts, and conscious constructions. In A. W. Melton \& E. Martin (Eds.). Coding processes in human memory. Washington, D.C: Winston, 1972.

PRIBRAM. K. H. Languages of the brain: Experimental paradoxes and principles of neuropsychology. Englewood Cliffs, N.J: Prentice-Hall, 1971.

Ratcliff, R. A theory of memory retrieval. Psychological Review, 1978, 85, 59-108.

Simon, H. A.. \& Feigenbaum, E. A. An information processing theory of some effects of similarity, familiarization, and meaningfulness in verbal learning. Journal of Verbal Learning and Verbal Behavior, 1964, 3, 385-396.

SkINNER, B. F. About behaviorism. New York: Vintage, 1976.

Tulving, E. Subjective organization in the free recall of "un related" words. Psychological Revien', 1962, 69, 344-354.

Tulving, E., \& Thомson, D. Encoding specificity and retrieval processes in episodic memory. Psychological Review, 1973, 80, 352-373.

WeChSLER. D. B. Engrams, memory storage, and mnemonic coding. American Psychologist, 1963, 18, 149-153.

Woodworth, R. S. Psychology. New York: Holt, 1929.

(Received for publication February 8, 1979.) 